INNOVATIVE CLEAN COAL TECHNOLOGY (ICCT)

\section{DEMONSTRATION OF INNOVATIVE APPLICATIONS OF TECHNOLOGY FOR COST REDUCTIONS TO THE CT-12.1 FGD PROCESS}

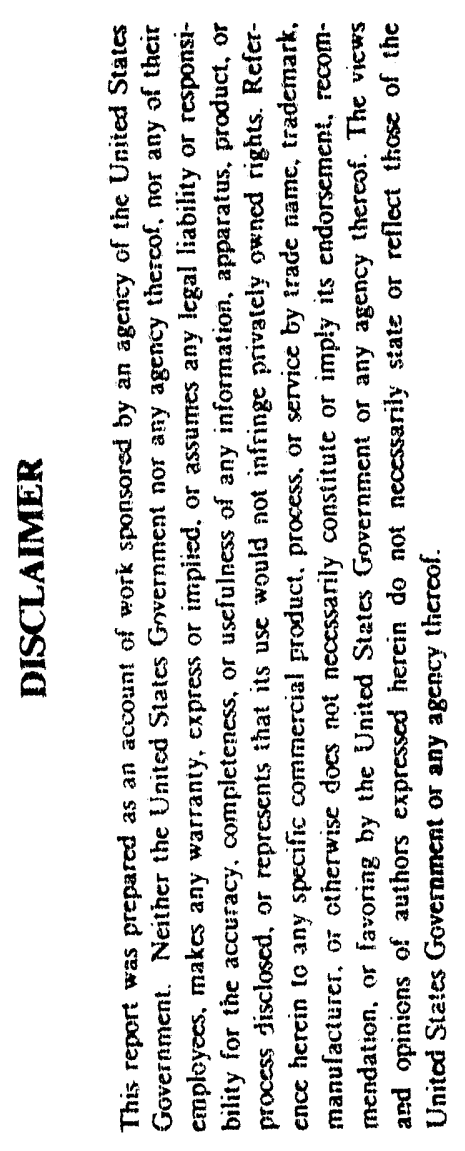

\author{
Quarterly Report No. I \\ For the Period \\ Aprit - June, 1990
}

August 6, 1990
DOE/PC/89650--T6

DE92 018191

Prepared by:

Southern Company Services, Inc.
800 Shades Creek Parkway
Birmingham, Alabama 35209

Patents Cleared by Chicago on August 1, 1990

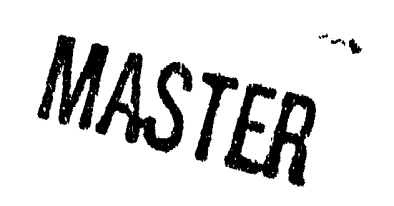

Se 
This report was prepared by Southern Company Services, Inc. pursuant to a cooperative agreement partialiy funded by the U.S. Department of Energy and neither Southern Company Services, Inc. nor any of its subcontractors nor the U.S. Department of Energy, nor any person acting on behalf of either:

(a) Makes any warranty or representation, express or implied with respect to the accuracy, completeness, or usefulness of the information contained in this report, or that the use of any information, apparatus, method, or process disclosed in this report may not infringe privately-owned rights; or

(b) Assumes any liabilities with repect to the use of, or for damages resulting from the use of, any information, apparatus, method or process disclosed in this report.

Reference herein to any specific commercial product, process, or service by trade name, trademark, manufacturer, or otherwise, does not necessarily constitute or imply its endorsement, recommendation, or favoring by the U.S. Department of Energy. The views and opinion of authors expressed herein do not necessarfly state or reflect those of the U.S. Department of Energy. 


\section{Section 1}

\section{SUMMARY}

The objective of this project is to demonstrate on a commercial scale several innovative applications of cost-reducing technology to the Chiyoda Thoroughbred-121 (CT-121) process. CT-121 is a second generation flue gas desulfurization (FGD) process which is considered by the Electric Power Research Institute (EPRI) and Southern Company Services (SCS) to be one of the most reliable and lowest cost FGD options for high.sulfur coal-fired utility boiler applications. Demonstrations of the following innovative design approaches will further reduce the cost and provide a clear advantage to CT. 121 relative to competing technology:

1. use of fiberglass reinforced plastic (FRP) to construct the absorber vessel, wet ducts, and chimney (stack),

2. elimination of flue gas reheat,

3. elimination of the need for a spare absorber, and

4. use of a single vessel to obtain simultaneous particulate and $\mathrm{SO}_{2}$ removal.

The demonstration will be performed at Georgia Power Company's Plant Yates Unit No. 1 (100 MW capacity) near Newnan, Georgia. The project will be funded by the U. 3. Department of Energy (DOE), SCS (on behaif of the entire Southern electric system), and EPRI. SCS is the participant responsible for managing all aspects of this project.

The project is being conducted in the following three phases:

Phase I - Permitting and Preliminary Engineering;

Phase II - Detailed Engineering, Construction, and Startup; and rinase III - Operation, Testing, and Disposition.

During the time prior to award and in the April-May 1990 quarter, activities in both Phase I and Phase II were initiated. In Phase I, cormitting ectivities were begun by both SCS and Georgia Power. Work on the Environmental Monitoring Plan continued based on the Environmental Monitoring Plan Outline submitted during the pre-award period. Preliminary engineering activities included setting the system design basis and submitting this basis to Chiyoda, interaction with Chiyoda to make the process flow diagram final, review of Chiyoda's basic engineering package, and development of a revised Critical Path Method (CPM) schedule for the Project's engineering and construction activities. Project engineering management al so developed a project specific management information system to track schedule and budget for engineering and cquipmient procurement. Construction management interacted with engineering to develop the integrated CPM schedule for engineering and construction. An overall management information system for the project was 
completed to monitor, schedule and budget for the entire project and to fulfill DOE reporting requirements. Negotiations with previousiy selected subcontractors were also completed. The Phase II activities were focused on preparation of specifications and inquiry packages for the long lead-time equipment. 
Section 2

INTRODUCTION

The Innovative Clean Coal Technology (ICCT) Program is designed to demonstrate clean coal technologies that are capable of retrofitting or repowering existing facilities to achieve significant reduction in sulfur dioxide $\left(\mathrm{SO}_{2}\right)$ and/or nitrogen oxides (NOx) emissions. The technologies selected for demonstration are capable of being commercialized in the $1990 \mathrm{~s}$ and are expected to be more cost effective than current technologies.

This ICCT project is jointly funded by the U.S. Department of Energy, the Electric Power Research Institute (EPRI), and by Southern Company Services (SCS) on behalf of the entire Southern electric system. The project's objective is to demonstrate innovative applications of technology for cost reduction for the Chiyoda Thoroughbred-121 (CT-121) process. The CT-12! process is a second generation fiue gas desulfurization (FGD) process that EPRI and SCS consider to be one of the least cost FGD processes in its current commercial configuration. Further cost reductions will only make this process more competitive and attractive to electric utilities.

The CT-121 process is a wet $F G D$ process that removes $\mathrm{SO}_{3}$, can achieve simultaneous particulate control, and can produce a salable by-product gypsum thereby eliminating solid waste production. Figure 1 shows a flow schematic of the process. CT-121 removes $\mathrm{SO}_{2}$ and particulate matter in a unique limestone-based scrubber called the Jet Bubbling Reactor (JBR). In the JBR, flue gas bubbles beneath the slurry, $\mathrm{SO}_{2}$ is absorbed, and particulate matter is removed from the gas. The agitator circulates slurry to ensure that fresh slurry is always available in the bubbling or froth zone so that SO, removal can proceed at a rapid rate. Air is introduced into the bottom of the JBR to oxidize the absorbed $\mathrm{SO}_{2}$ to sulfate, and limestone is added to neutralize the acid slurry and form gypsum. The JBR is designed to allow time for complete oxidation of the $\mathrm{SO}_{2}$, for complete reaction of the limestone, and for growth of large gypsum crystals. The gypsum slurry is continuously withdrawn from the J8R and can be dewatered in a gypsum stack. The stacking technique involves filling a dyked area with gypsum slurry, allowing the gypsum solids to settle, and removing clear liquid from the top of the stack and returning it to the process.

The CT-121 process is in commercial use in Japan and in the United States. At the University of Illinois, a $45 \mathrm{MW}$ process began operations in ig88 on a stoker boiler, which is not a typical utility boiler. In Japan, commercial CT-121 processes are used to treat the flue gas from boilers which burn oil or low-sulfur coal. Some of the oil-fired units do not include particulate control devices upstream of the CT-121 processes.

The purpose of this ICCT project is to demonstrate the process on highash and high-sulfur U.S. coal using several design modifications that will reduce the estimated cost of the present CT-121 process by 23 percent for power plant retrofit applications and 50 percent for new power plant installations. This will be accomplished while maintaining 90 percent $\mathrm{SO}_{2}$ 


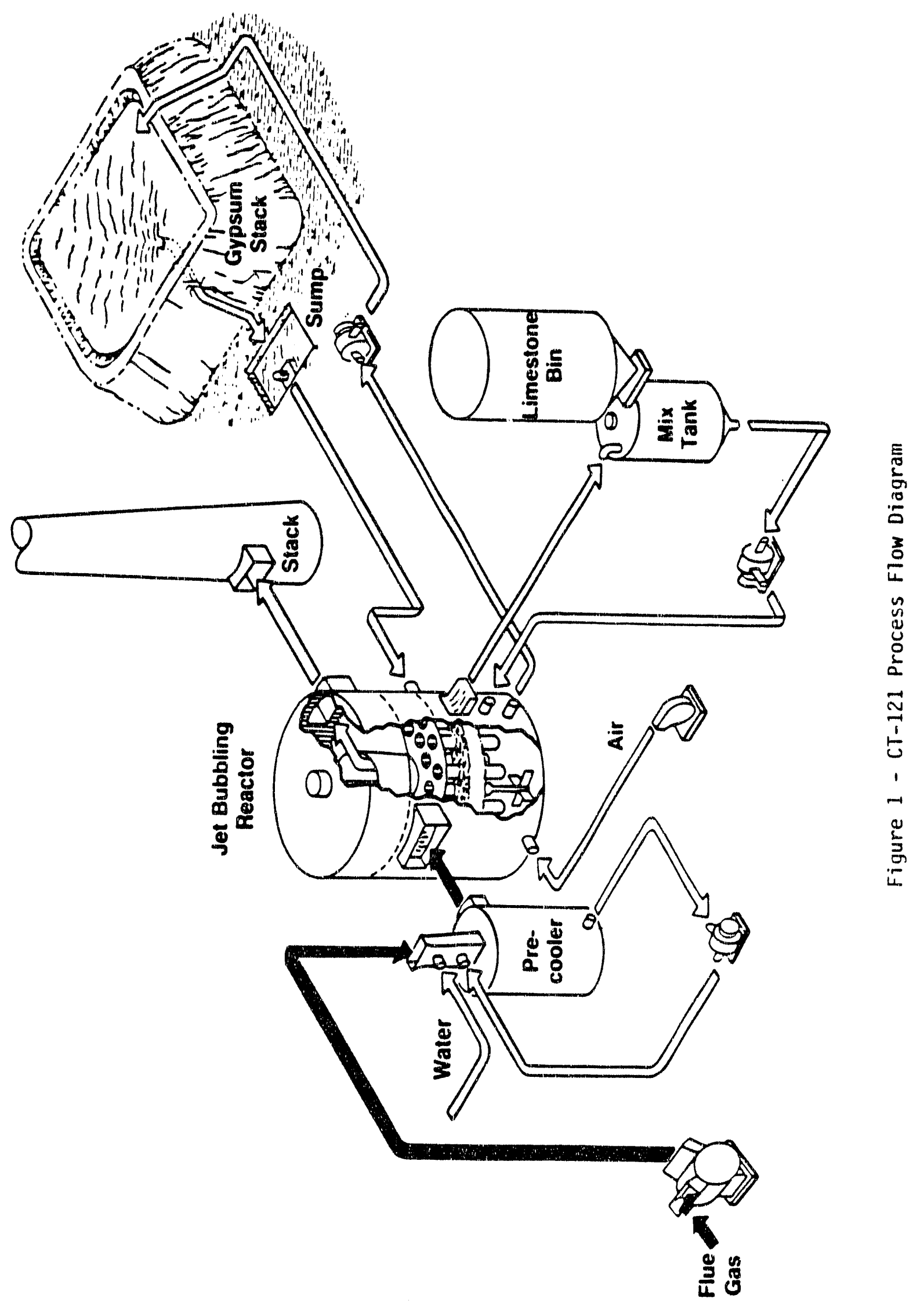


removal and high particulate removal efficiency. A reuseable gypsum byproduct wi 11 also be produced during the project.

The Major cost-reducing design changes to be demonstrated are:

- using less expensive materials of construction,

- eliminating a spare absorber module,

- eliminating fiue gas reheat, and

- combining $\mathrm{SO}_{2}$ and particulate removal in a single vessel.

Utility scale units with the CT-121 processes currently include a prescrubber for control of soluble chloride concentration and use JBRs made of stainless steel, which is relatively expensive. Typically, outlet ducts are lined or made of alloys, and the chimney is lined. Liners have to be replaced after a period of time which adds additional expense and inconvenience. For this demonstration project, the prescrubber. JBR, outlet duct, and chimney will be made of solid fiberglass-reinforced plastic (FRP) which is unaffected by chloride or other corrosion mechanisms normally experienced in FGD processes. A successful demonstration of FRP in this project will eliminate the need for a prescrubber in the CT-121 process and will demonstrate a material which is less expensive that $316 \mathrm{~L}$ stainless steel.

Current Federal New Source Performance Standards (NSPS) require that spare scrubbers normaliy be installed on utility FGD systems. This project is intended to demonstrate that the CT-121 process using a JBR made of FRP is highly reliable and does not require a spare absorber module to effectively control $\mathrm{SO}_{3}$ emissions.

Another cost-saving modification to be demonstrated in this project is the elimination of flue gas reheat downstream of the scrubber. The flue gas leaving any scrubber is at its water dewpoint, and, without reheat, subsequent cooling in the ductwork and stack causes moisture to condense into small dropleis. These water droplets absorb traces of $\mathrm{SO}_{2}$ and form acid droplets that cause severe corrosion in ducts and stacks. In addition, these droplets tend 1,0 fall near the base of the stack, causing damage to surrounding struc:ures and vehicles. To prevent these problems, this project will use operating techniques and equipment designs that will eliminate the need for cost"y reheating.

The final cost-saving modification is simultaneous removal of $\mathrm{SO}_{2}$ and particulate matter in the JBR. Typically, an electrostatic precipitator or fabric filter is used upstream of the scrubber to remove particulate matter. In the CT-121 process, greater than 90 percent of the $\mathrm{SO}_{2}$ and 99 percent of the particulate matter in the entering flue gas can be removed in the JBR. When used in new power plants, the elimination of the ESP or fabric filter will result in substantial capital and operating cost reductions. Thus, the CT-121 process provides a cost effective alternative to conventional wet $F G D$ systems.

This project will be performed at Georgia Power Company's Plant Yates, Unit No. 1. This plant is located about 40 miles southwest of Atlanta near Newnan and Carrolition. The CT-121 process to be installed for this 
demonstration project will treat the whole flue gas stream generated by the $100 \mathrm{MW}$ Unit 1 boller. The coal to be burned during the project will be a blend of Illinois 5 and 6 coals and will contain between 2.5 and 3 percent sulfur coal.

The demonstration project will be conducted over an 81 -month period with project activities including environmental monitoring, permitting, design, construction, operation, process evaluation, and gypsum by-product evaluation. The project is organized irito three phases: (1) Phase I - Permitting and Preliminary Engineering; (2) Phase II - Detailed Engineering, Construction, and Startup; and (3) Phase III - Operation, Testing, and Disposition. Phase I is scheduled for 8 months, Phase II is scheduled for 27 months with a sixmonth overlap with Phase I, and Phase III is scheduled for 52 months. Operations are planned for 24 months with the remainder of Phase III activities dedicated to gypsum byproduct utilization and gypsum stack groundwater monitoring studies. The cooperative agreement was signed April 2, 1990, and the project completion date is projected to be mid-1996. The total estimated project costs are $\$ 35,843,678$. The co-funders are SCS $(\$ 11,297,032)$, DOE $(\$ 17,546,646)$, and EPRI $(\$ 7,000,000)$. 
PROJECT DESCRIPTION

Within the three phases of the project, the following tasks will be conducted to effectively demonstrate a reduced-cost $\mathrm{CT}-121$ process:

Phase I - Permitting and Preliminary Engineering

Task 1 - Development of Environmental Monitoring

Task 2 - Permitting Activities

Task 3 - Preliminary Engineering

Task 4 - Gypsum Stack Site Characterization and

Task 5 - Process Engineering Support

Task 6 - Georgia Power Engineering Coordination

Task 7 - Project Management and Reporting

Task 8 - Preliminary Gypsum Stacking and Byproduct Studies

Phase II - Detalled Design, Construction, and Startup

Task 1 - Detalled Design Engineering

Task 2 - Process Engineering Support

Task 3 - Georgia Power Engineering Coordination

Task 4 - Construction

Task 5 - Test Plan Development

Task 6 - Training of Operations and Maintenance

Personnel

Task 7 - Startup

Task 8 - Baseline Groundwater Monitoring

Task 9 - Environmental Data Management and Reporting

Task 10 - Project Management and Reporting

Task 11 - Phase II Gypsum Stack Design and Byproduct Studies

Phase III - Operations, Testing, and Disposition

Task 1 - Operations and Maintenance

Task 2 - Process Evaluation

Task 3 - Gypsum Stacking and Byproduct Evaluation

Task 4 - Groundwater Monitoring

Task 5 - Environmental Data Management and Reporting

Task 6 - Economic Analysis

Task 7 - Disposition

Task 8 - Project Management and Reporting 
Section 4

PROJECT STATUS

Per agreement with DOE, SCS began some preliminary activities prior to the official signing of the Cooperative Agreement in order to maintain the project schedule. The Cooperative Agreement was signed by DOE on April 2, 1990. Progress during the first quarter (and the period prior to signing of the Cooperative Agreement) is summarized below.

\section{PHASE I - PERMITTING AND PRELIMINARY ENGINEERING}

\section{Task 1 - Develonment of Environmental Monitoring Program}

The Environmental Monitoring Plan Outline developed during the pre-award period was accepted by DOE as the final outline. Work has begun on the development of the Environmental Monitoring Plan, including the quality assurance/quality control project plan and sampling and analyses procedure manual.

\section{Task? - Permitting Activities}

The permits required for the project are in three catego fes: (1) those required during construction, (2) air permits required for operation, and (3) water permits for operation of the process and the gypsum stack. Georgia Power and SCS have initiated efforts in all three areas. Information regarding emissions during constuction nas been collected from the fiberglass manufacturer, and initial discussions have been held with the state. A preliminary opinion that no air permit is required for construction has been given verbally by the State. Georgia Power has sent a letter documenting estimated emissions and is waiting for a formal determination from the state. The fiberglass manufacturer will be responsible for disposal of any solid waste which is categorized as hazardous.

Georgia Power and SCS have also begun work on the air permit application required for operations. A draft application has been prepared, and Georgia Power is waiting for the process flow diagram to be finalized before the air permit application is completed and submitted to the State.

\section{Task 3 - Prel iminary Engineering and Task 5 - Process Engineering Support}

Progress on a number preliminary engineering activities was accomplished during the quarter. Data -- including flue gas flow rate and composition, unit heat rate, and service water composition -- were collected from Plant Yates. These data were included in a design basis document which was transmitted to Chiyoda in January. Chiyoda's basic engineering package was received in 1ate Apri1, and SCS began its review at that time. Communications between SCS and Chiyoda continued through the quarter to clarify and refine the process design and equipment layout issues. Based on this progress, the process flow diagram is essentially complete at this time. SCs engineers also 
traveled to the 45 MW CT-121 process located in Champaign, I11inois to gain a better understanding of the design requirements.

A project specific management information system for engineering and equipment procurement was also developed during the initial stages of the project. As part of the initial effort, Engieering and construction input were collected and coordinated to produce an integrated engineering and construction schedule for the Yates project. The MIS system, in conjunction with the CPM schedule, allows expenditures and commitments to be tracked and controlled. Engineering submitted reports of schedule and budget status monthly to the Project Manager. Weekly meetings of the lead discipline engineers were held to facilitate communications.

\section{Task 4 - Gypsum Stack Site Characterization and Groundwater Well siting Activities}

Activities to support the gypsum stack perritting effort were begun during the quarter. Soil samples were collected and analyzed and geot:-innical information was assembled. The local clay was tested for possibie use as liner material. Preliminary groundwater well locations have been proposed and plans made to discuss well location with the State. Plans to install the wells were also begun.

\section{Task 6 - Georgia Power Engineering Coordination}

A number of meetings have been held between SCS and Georgia Power Construction and Plant personnel. Frequent conversations between the lead discipline engineers at SCS and plant engineering staff have been conducted to ensure that the plant perspective has been considered in engineering and procurement decisions.

\section{Task 7 - Project Management and Reporting}

The first activity undertaken in this task was development of an overall project management information system capable of tracking overall budget and schedule information. This system is in place and is being used to control budget and schedule and to help fulfill DOE reporting requirments. Monthly ripuits have been submitted as has the Project Evaluation Plan for the first budget period.

In addition, contracts with all named subcontractors (except Ershigs) have been negotiated and are in place. The Ershigs FRP equipment manufacturing contract has not been completed as yet because of it: complexity and close ties to some of the engineering activities not yet completed. While this contract negotiation is somewhat behind the planned schedule, the planned October 15 start date for on-site FRP manufacturing plant set should not be delayed.

Kickoff meetings with Georgia Power and other contractors have been held, and coordination meetings of all aspects of the project have been conducted on a monthiy basis. 


\section{Task 8 - Preliminary Gyesum Stacking and Byproduct Studies}

In this task, SCS has coordinated with Ardaman and Associates to collect site and laboratory data required to perform gypsum stack design calculations. Clay, local to the Plant Yates site, has been evaluated for its potential use as a gypsum stack liner material. This information will be presented to the State, and liner decision will be reached.

Preliminary agricultural studies with gypsum from other FGD sites in the United States have begun at the University of Georgia. The results of these preliminary tests will be used to complete final test plans for the agricultural studies with the Plant Yates CT-121 gypsum.

PHASE II - DETAILED DESIGN, CONSTRUCTION, AND STARTUP

\section{$\frac{\text { Task 1 - Detailed Engineering. Task } 2 \text { - Process Engineering Support, and }}{\text { Iask } 3 \text { - Georgia Power Engineering Coordination }}$}

Because of the tight schedule planred for this projeci, some detailed engineering activities have begun concurrently with preliminary engineering. The first activities undertaken were specification and procurement efforts for the long lead-time equipment. Other activities in support of the first construction activities have also begun. The following summarize progress in the detailed engineering task:

- Developed specifications and sent inquiry packages to vendors for fan, limestone pulverizer system, $115 \mathrm{kV}$ transformer, and control building. Received and began evaluation of bids for this equipment.

- Developed specifications and sent inquiry packages to vendors for the fan motor, $4160 \mathrm{~V}$ and $480 \mathrm{~V}$ motor control centers, $4160 \mathrm{~V} / 480 \mathrm{~V}$ power transformer, and $4160 \mathrm{~V}$ and $480 \mathrm{~V}$ switchgear.

- Held weekly meetings among Civil, Electrical, I\&C, Mechanical, and Process Engineering Disciplines to facilitate communications.

- Began developing specifications for the data aquisition and control systems and for the limestone conveyor system.

- Communicated with Ershigs and Chiyoda regarding the construction of the FRP vessels. Identified important issues and began to resolve these in preparation for final negotiations with Ershigs.

\section{Task 4 - Construction}

While not specifically identified in Phase I as preliminary activities, a number of preliminary construction activities were conducted in the initial 
months to support the project. A constuctiblitty review was performed to establish the most effective way of completing the project. An activity coding system was developed to form the basts of the construction scheduling and control system. Construction management also developed a final construction pian and worked with Engineering management to develop the master engineering and construction project schedule (Rev. 0$)$. Construction managemelit personnel have attended monthly project meetings to ensure that. Construction's persiective is incorporated in all important engineering decistons. 


\section{Section 5}

\section{PLANNED ACTIVITIES}

\section{planned:}

During the July - August, 1990 quarter the following activities are

- Continue permitting acnivities. Submit draft air permit to State of Georgia. Meet with State to discuss gypsum stack Iiner requirments and groundwater monitoring requirements.

- Submit draft Environmental Monitoring Plan to DOE. Include a Sampling and Analysis Manual and a Quality Assurance/Quality Control Plan.

- Complete preliminary engineering and write the system design basis document.

- Hold froject groundbreaking ceremony at Plant Yates.

- Hold first project review cummittee meeting with DOE and EPRI.

- Award limestone pulverizur system, fan, fan motor, control building, $115 \mathrm{kV}$ transformer, $4160 \mathrm{~V}$ and $480 \mathrm{~V}$ motor control centers, $4160 \mathrm{~V} / 480 \mathrm{~V}$ power transformer, and $4160 \mathrm{~V}$ and 48CV switchgear.

- Finalize contract with Ershigs for FRP equipment. Review intial drawings and begin foundation design for JBR, prescrubber, chimney, and ductwork.

- Prepisre specifications for steel ductwork and structual steel and issue inquiry package.

- Complete spectfication and issue inquiry packages for vertical and horizontal centrifugal pumps. Receive bids and begin evaluations.

- Complete specifications for data aquisition and plant control systems and issue inquiry package.

- Begin preparation of continuous emissions monitoring system specification.

- Develop specifications, issue inquiry package, receive bids, and begin evaluations for limestone conveyor system. 


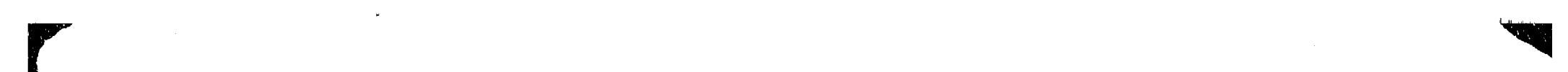


